\title{
EFFECTS OF PHENYLEPHRINE DURING HALOTHANE ANAESTHESIA IN MAN
}

\author{
J. W. R. MCINTYRE, F.F.A.R.C,S. ${ }^{*}$
}

VASOPRESSORS are always available for the anaesthetist in the operating room, and though there may be some difference of opinion regarding the benefit their use confers on the patient, nevertheless, with the sudden onset of hypotension, intravenous injections of a vasopressor are sometimes given. Unfortunately, these circumstances are often not suitable for critical observation of drug effects, and the part played by the vasopressor in the successful or unsuccessful outcome of the situation is not available for later scrutiny. Clinical experiences with phenylephrine were described by Tainter $^{1}$ in 1933, and since that time it has been considered a safe and effective drug. The object of this paper is to consider the intravenous use of phenylephrine during halothane anaesthesia, with reference to its effects on cardiac rhythm. Some observations have already been made on this subject, both in man and in animals. In man, Chang, ${ }^{2}$ Wyant, ${ }^{3}$ and Catenacci ${ }^{4}$ have each noted the occasional occurence of ventricular extrasystoles. Stephen ${ }^{5}$ produced no cardiac arrhythmias in dogs and monkeys with the drug, but Loehning ${ }^{6}$ observed a high incidence of arrhythmias including ventricular tachycardia and fibrillation in dogs. Catenacci ${ }^{4}$ commented on the marked bradycardia evident in many instances in dogs, as well as the occurrence of ventricular tachycardia and ventricular extrasystoles. Thus it appears that any hazard to the patient which may exist lies in the occurrence of bradycardia, or alterations in cardiac rhythm. These changes may be of little significance in a patient under normal circumstances, when the administtation of a vasopressor is unlikely, and yet may be of importance in circumstances when such a drug may be used.

The bradycardia is of reflex origin, and stimulation of the carotid sinus baroreceptors has been shown to have a reflex negative inotropic effect upon the atrial and ventricular myocardium. ${ }^{7}$ The change from sino-atrial to atrioventricular nodel rhythm during halothane anaesthesia in man is associated with a fall in systemic arterial pressure and a rise in central venous pressure. ${ }^{8}$ The deleterious effects of various arrhythmias on cardiac output have been reviewed by Corday. ${ }^{9}$ Haemodynamic alterations of this nature superimposed on an already abnormal state could cause a deterioration in the patient's condition. These considerations form the basis for the present investigation.

\section{Method}

Fifty normothermic patients with no known cardiovascular or respiratory disease, and receiving no additional medications that influence cardiac rhythm, were anaesthetized with the sequence thiopentone, succinylcholine, intubation,

Department of Anaesthesia, University of Alberta Hospital, Edmonton, Alberta. 
nitrous oxide:oxygen 1:1, halothane 1 to 3 per cent. All patients were horizontal in the supine position. Succinylcholine infusions, gallamine, or curare were administered where necessary. Artificial ventilation 25 to 50 per cent in excess of the Radford Nomogram value for each patient was maintained with a mechanical ventilator in a semi-closed circle absorber system. The fall in systemrc blood pressure that occurred was associated primarily with the administration of halothane, and ventilation and blood loss were considered of less significance in this respect. Phenylephrine was administered when the systolic blood pressure was 48 to 80 per cent of the pre-operative value. It was injected into an antecubital vein during or following surgery, at a time when no specific stimulus that might produce cardiovascular disturbance was taking plice. A 0.1 per cent solution was used, the dose being calculated on a body-weight basis. Patients weighing 100-115 pounds received $0.15 \mathrm{mg}$., and dosage was increased by $0.025 \mathrm{mg}$. for each 15 pounds over this weight. In some instances the dose was doubled-in which case a patient weighing $145-160$ pounds would receive $0.45 \mathrm{mg}$.; or it was halved, in which case the amount would be $0.11 \mathrm{mg}$. All injections were followed by $10 \mathrm{ml}$. of dextrose in saline. Continuous Lead II E.C.G. recordings were taken with a Sanborn apparatus for three minutes after injection, and the blood pressure was measured by auscultation at thirty-second intervals during this time.

\section{Results}

Systolic blood pressure before and after injection of phenylephrine is represented in Figure 1 as a percentage of the patients' normal value. It will be seen that except in one instance a pressor effect was always observed, and only with the high dose of phenylephrine- $0.45 \mathrm{mg}$. for a patient weighing $145-160$ poundswere changes recorded that were markedly in excess of the preoperative values. It should be noted that peak pressures may not have been recorded, nor was the rate of increase of pressure measured.

Arrhythmias occurred in two of the fifty cases. Approximately 80 seconds after

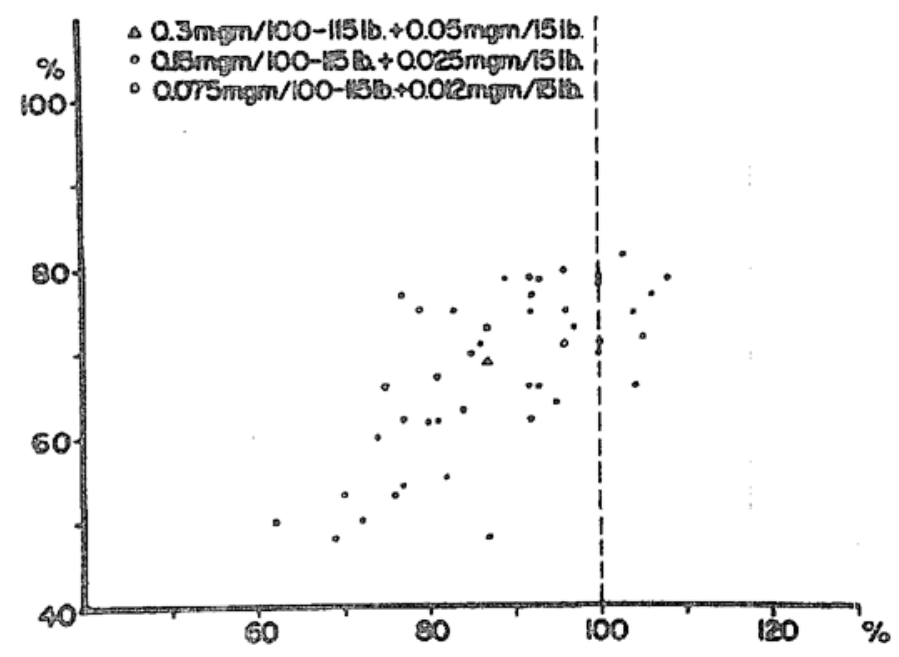

Figure 1. Ordinate: Percentage of preoperative systolic pressure when phenylephrine administered. Abscissa: Percentage of preoperative systolic pressure after administration of phenylephrine. 
injection, isolated ventricular extrasystoles occurred intermittently during a period of thirty seconds. The highest dosage of phenylephrine was used in both, and in one case the highest recorded pressure was in excess of the normal value. The other patient had a $\mathrm{pH}$ of 7.28, a $p \mathrm{CO}_{2}$ of $47 \mathrm{~mm} . \mathrm{Hg}$, a $p \mathrm{O}_{2}$ of $69 \mathrm{~mm}$. $\mathrm{Hg}$, and bicarbonate of $20.3 \mathrm{mEq}$./litre, representing a base deficit of $4.6 \mathrm{mEq}$./litre.

Although in four cases there was a transient increase in pulse rate of up to eight beats per minute, ultimately the rate was unchanged or reduced in all but one. The incidence of bradycardia is portrayed in Figure 2, and it can be seen that the most marked reduction in pulse rate was associated with the highest phenylephrine dosage, although it is also evident that the higher dosage is not necessarily associated with bradycardia.

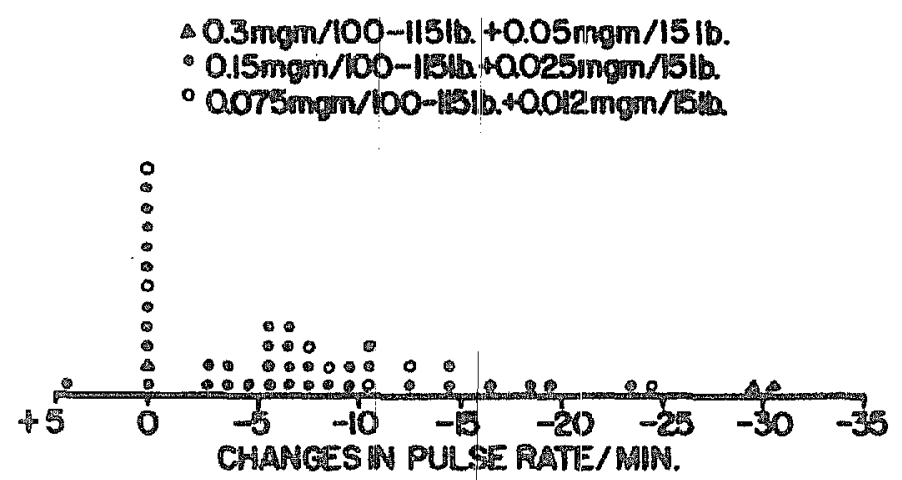

FIGURE 2

Drug dosage is frequently estimated on a body-weight basis for purposes of convenience, rather than because there is a reliable relationship between body weight and anticipated pharmacological effect. An inference that any reduction in pulse rate is dependant only on the phenylephrine dosage would be misleading. In clinical anaesthesia, many factors must be taken into account in addition to a direct effect of the drug on the sino-auricular node-a possibility suggested by $\mathbb{K e y s}^{10}$ in 1940 but never substantiated. These factors include the degree of maintained stimulation and rate of change of stimulation of baroreceptors in the carotid sinus and aortic arch, stimulation of pulmonary vessel receptors and stretch receptors in the myocardium, receptor thresholds, the transmission of impulses from receptors to the brain, the response of the brain to these stimuli, and the efferent pathways to the sino-auriciular node. The force and rate of receptor stimulation is directly related to changes in blood pressure and blood distribution. The larger the dose of vasopressor, the more marked these changes are likely to be. Receptor thresholds, the transmission of impulses and the reflex cardiac responses to them are influenced by the age of the patient and by other drugs present.

Millar ${ }^{11}$ has presented evidence that the discharge of impulses in carotid baroreceptors is increased during halothane anaesthesia, while Morse and his colleagues $^{12}$ have reported an initial sensitization followed by a normal or below-normal frequency response.

Halothane has also been shown to possess a central effect, reducing sympathetic activity and permitting an increasing para-sympathetic activity. ${ }^{13}$ On the efferent side, reflex cardiac slowing can be blocked by atropine; as far back as 1939 
Brunner ${ }^{14}$ advocated the use of atropine with phenylephrme for this reason The yariation in degree of bradycardia occurring in the cases/reported here is due not only to variation in patients but also to the response of blood pressure to dufferences in the use of gallamme atropine , and halothane durng the different anaesthetics

There is no doubt that atropinzation is a valuable protection against brady cardia but the followng case demonstrates an undesirable result associated with $^{\text {th }}$ the use of this drug A healthy woman 24 years of age and werghing 125 pounds was anaesthetized with thropentone nitrous oxde oxygen halothane and curare by the technique already described Her normal blood pressure was 110/60, and during the course of anaesthesia her pressure was recorded at 60/40 the pulse at 68 whule the EE,G recording at this tume unducated Pattern 4 ( $\left.F_{1 g} 3\right)$ a moderate depth of anaesthesia according to the classification of Gam and Paletz ${ }^{15}$

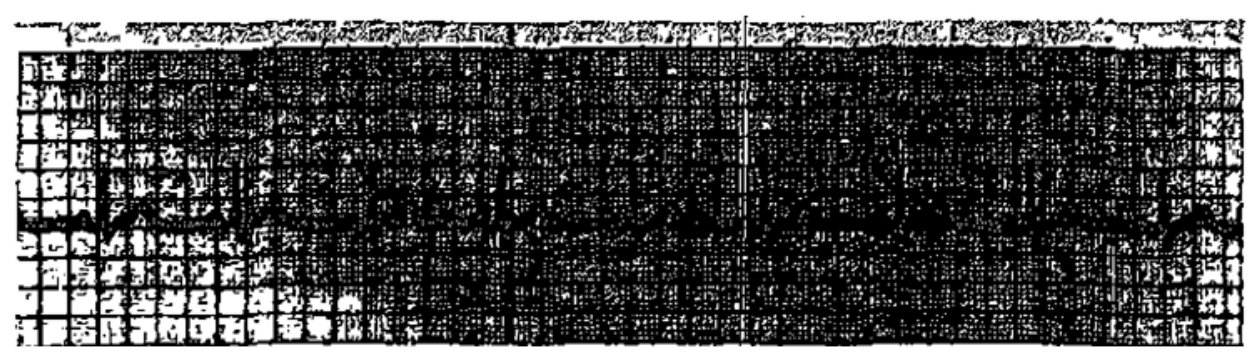

Figure 3 E C G lead II pror to/adminstration of phenyl ephrine

Phenylephrine $0175 \mathrm{mg}$ was administered and durng the course of the next three ininutes the pressure rose to $65 / 50$ and the pulse fell from 68 to 65 beats per minute The halothane was discontinued and a few minutes later the E. $E$ indicated Pattern 2 with little change in pulse or blood pressure Now phenyl ephrine $035 \mathrm{mg}$ was administered double the previous dose The maximum blood pressure recorded was $140 / 100$ and the cardac rate gradually slowed to a minimum of 39 beats per minute sinus rhythm being maintaned Atropine $06 \mathrm{mg}$ was adminstered intravenously The ECG changes are illustrated in Figure 4

Tracing A shows the maximum bradycardia following $035 \mathrm{mg}$ of pheny ephrine The appearance of $U$ waves is of doubtful significance It is possible that in this instance they are associated with an increase in serum potassium known to be an effect of catecholammes on the liver ${ }^{10}$ After the administration of atropine there was no evidence of cardiac slowing but only a gradual increase un sinus rate

Tracing $B$ shows the changes occurring half a minute after the adminstration of atropine

Tracings $C$ and $D$ show the rhythm during the ensuing two minutes

Tracing $E$ allustrates part of a gradual return to the normal rhythm that was attined four minutes later

It appears that alterations in refractormess or conduction prevented the main tenance of sinus rhythm after the release from vagal impulses following atropine 


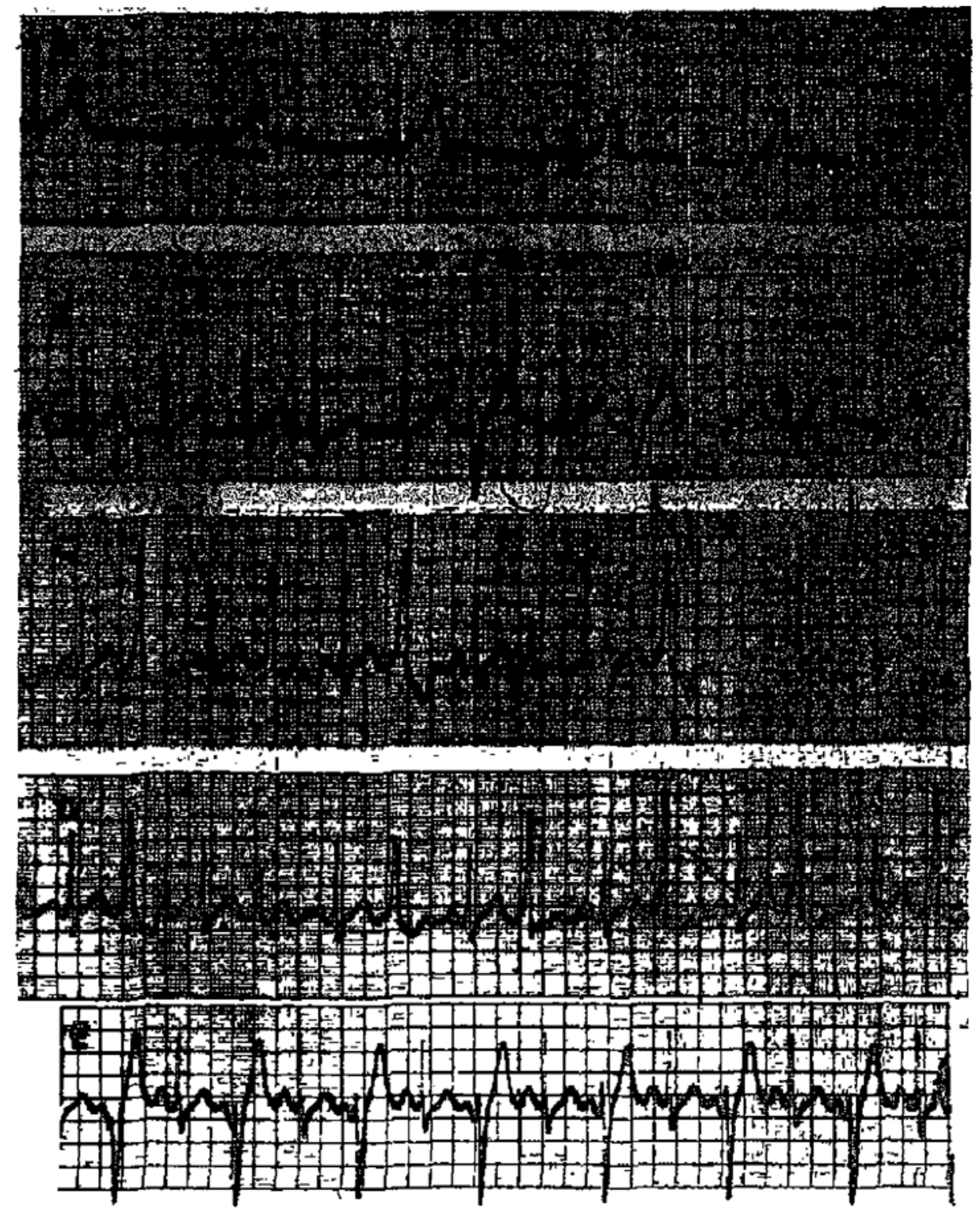

Figure 4

administration and the atrioventricular block permitted the origin of impulses from varying sites in the A V node or Bundle of His

Simlar changes have been described by Averill ${ }^{1}$ when atropme was admins tered to conscious volunteers and by Jones and his colleagues ${ }^{18}$ following the administration of atropine during halothane an resthesia The fact that ventricular cxtrasystoles appeared more frequently in the present case report is perhaps another indication that though phenylephrine in comparison with some other vasopressors is relatively free of direct iction on the myocardium it is not completely devord of such effects

The conclusions that can be drawn from these results ire limited by the fact that the disturbances of circulation form which the majonsty of these patients suffered differed in quality and degree from those for which the administration of a vasopressor might be seriously considered and in the latter instance the blood pressure response for a given dosage might be smaller However under these other circumstances the heart might also be more likely to respond in an undesirable manner No eidence has been presented that the presence of halo thane mcreases the hazard of phenylephrine but it should be borne in mind that this drifg does sensitize the myocardium to catecholamines 
The very low incidence of arrhythmias in the cases presented) is not evidence against the caution advised by various authors regarding the use of vasopressors - particularly by Catenacci with reference to halothane-but rather an indication of the influence of drug dosage. If the administration of phenylephrine to a patient suffering from hypotension is considered desirable in the presence of halothane, doses should be in increments of $0.1-0.2 \mathrm{mg}$. for a 150-pound patient, and successive injections should be avoided unless it is certain that the preceding one has reached the circulating blood. Such dosage could be facilieated by having available suitably dilute solutions.

\section{SUMMARY}

Phenylephrine in varying dosage was administered to patients during surgery under anaesthesia with nitrous oxide:halothane and relaxant, when the systolic blood pressure had fallen to 48 to 80 per cent of the preoperative value. Isolated ventricular extrasystoles occurred in two of fifty cases, and a varying degree of bradycardia was demonstrated. A case report is presented in which the intravenous injection of atropine to correct a reflex bradycardia resulted in an atrioventricular rhythm, and attention is drawn to the effects of such changes on the cardiac output. Phenylephrine may not have a place in the treatment of hypotension during general anaesthesia, but it is concluded that if the drug is to be administered to a patient weighing approximately 150 pounds $(70 \mathrm{~kg}$.) anaesthetized with halothane, increments of $0.1-0.2 \mathrm{mg}$. should be used.

\section{RéSumé}

Des opérés sous anesthésie au protoxyde-halothane et myorésolutifs ont été traités à la néo-synéphrine à doses variables pour des chutes de tension artérielle de 48 à 80 pour cent par rapport à la tension pré-opératoire. Des extrasystoles ventriculaires isolées se sont produites chez deux des cinquante cas traités, et on a observé de la bradycardie à des degrés variables. Nous présentons l'histoire d'un cas où une injection intraveineuse d'atropine pour corriger une bradycardie d'origine réflexe a produit un rythme auriculoventriculaire; nous attirons lattention sur les effets de ces changements sur le débit cardiaque. Il est possible que la néo-synéphrine n'ait pas sa place dans le traitement de l'hypotension au cours de l'anesthésie générale, mais on doit conclure que si on l'utilise chez un malade d'environ 150 livres, il faut injecter de 0.1 à $0.2 \mathrm{mg}$.

\section{REFERENCES}

1. Tainter, M. L. \& Stockton, A. B. Comparative Actions of Sympatho-mimetic Compounds: Circulatory and Local Actions of Optical Isomers of Metasynephrin and Possible Therapeutic Applications. Am. J. M. Sc. 185: 832 (1933).

2. Cilang, J.; Macartney, H. H.; \& Graves, H. B. Clinical Experience with Fluothane, a New Non-explosive Agent. Canad. Anaesth. Soc. J. 4: 187 (1957).

3. Wyant, G. M.; Meraman, J. E.; Kilduff, C. I.; \& Thomas, E. T. The Cardiovascular Effects of Halothane. Canad. Anaesth. Soc. I. 5: 384 (1958).

4. Catrenacci, A. J.; Dipalma, J. R.; Andenson, J. D.; \& KInG, W. E. Serious Arrhythmias with Vasopressors during Halothane Anaesthesia in Man. J.A.M.A. 183: 662 (1963). 
5. Stephen, C. R.; Margolis, G.; Fabian, L. W.; \& Bourgeois-Gavardin, M. Laboratory Observations with Fluothane. Anesthesiology 19: 770 (1958).

6. Loenning, R. W. \& Czonny, V. P. Halothane-Induced Hypotension and the Effect of Vasopressors. Canad. Anaesth. Soc. J. 7: 304 (1960).

7. De Geest, Hilame; Levy, Matthew N.; \& Zieske, Harrison Jr. Carotid Sinus Baroreceptor Reflex Effects upon Myocardial Contractility. Circulation Res. 327: 15 (1964).

8. Laver, Myron B. \& Turndorf, Herman. Atrial Activity and Systemic Blood Pressure during Anaesthesia in Man. Circulation 28: 63 (1963).

9. Conday, Eliot \& Inving, David W. Disturbances of Heart Rate, Rhythn, and Conduction. Philadelphia: Saunders (1961).

10. Keys, A. \& VIOLANTE, A. Production of Bradycardia in Normal Man by Neosynephrine ( 1 alpha-hydroxy-beta-methoamino 3 hydroxy ethyl benzine hydrochloride). Proc. Soc. Exp. Biol. \& Med. 44: 4 (1940).

11. MILLAR, R. A. \& BisCOE, T. J. The Effect of Halothane on Baroreceptors. Lancet 2: 765 (1963).

12. Monse, H. T.; Price, M. L.; \& Price, Henry L. Effect of Halothane on Systemic Baroreceptors. Fed. Proc. 22: 187 (1963).

13. Price, Henry L.; Linde, Harry W.; \& Morse, Howard T. Central Nervous Actions of Halothane Affecting the Systemic Circulation. Anesthesiology 24: 770 (1963).

14. Brumner, Robbie S. \& de Takats, Geza. The Use of Neosynephrine in Spinal Anaesthesia. Surg. Gynec. \& Obstet. 68: 1021 (1939).

15. GaIN, E. A. \& Paletz, S. G. An Attempt to Correlate the Clinical Signs of Fluothane Anaesthesia with Electroencephalographic Levels. Canad. Anaesth. Soc. J. 4: 289 (1957).

16. Vassalle, M., quoted in Price, Henry L. \& Cohen, Peter J. Effects of Anesthetics ón the Circulation. Thomas (1964) p. 119.

17. Avernz, K. H. Less Commonly Recognized Actions of Atropine on Cardiac Rhythm. Am. J. M. Sc. 237: 304 (1959).

18. Jones, R. E.; Deutsch, S.; \& TuRndorf, H. Effects of Atropine on Cardiac Rhythm in Conscious and Anaesthetized Man. Anesthesiology 22: 67 (1961). 